\title{
Factors Influencing Consumer Intention to Subscribe to the Premium Music Streaming Services in China
}

\author{
Victor Chang, Teesside University, Middlesbrough, UK \\ (iD) https://orcid.org/0000-0002-8012-5852 \\ Yifan Yang, Xi'an Jiaotong-Liverpool University, Suzhou, China \\ Qianwen Ariel Xu, Teesside University, Middlesbrough, UK \\ Chang Xiong, Xi'an Jiaotong-Liverpool University, Suzhou, China \\ (iD https://orcid.org/0000-0001-8392-4740
}

\begin{abstract}
This study investigates the causes impacting the consumers' intention to subscribe to the premium music streaming services in China. An integrated model called the theory of streaming service acceptance (TSSA) is proposed to explain and predict premium music streaming service subscription behaviors. The TSSA consists of four constructs: attitude, descriptive norm, injunctive norm, and perceived behavioral control. The research data was collected in the form of an online survey in China with 120 respondents. Then, interviews were conducted to collect qualitative data from 20 participants. An explanatory sequential mixed method was implemented, and the PLS-SEM technique was used to analyze the survey data. The results showed that all constructs in modified research mode, including attitude, injunctive norm, and perceived behavioral control except descriptive norm are indicative predictors for a person's intention toward premium music streaming services' subscription. Significant practical inspirations from the perspective of music streaming services providers are also summarized.
\end{abstract}

\section{KEYWORDS}

Consumption-Based Model, Descriptive Norm and Injunction Norm, PLS-SEM, Premium Music Streaming Service

\section{INTRODUCTION}

\subsection{Industrial Background}

For nearly twenty years, the music industry has experienced a drastic change, including product upgrades, shifting consumption patterns and marketing strategies with the rapid improvements of Information and Communication Technology (ICT). Consumer demand for music has not changed. The change is the new products and new consumption patterns born out of the emerging of new information technology. Digital music is the product of the development of Internet technology, which is different from physical music. In China, physical music records such as phonograph records, CDs and magnetic tapes are gradually disappearing in people's lives and markets. These physical music records only occupy a minor part of the music market or become collections of a few enthusiasts. In 


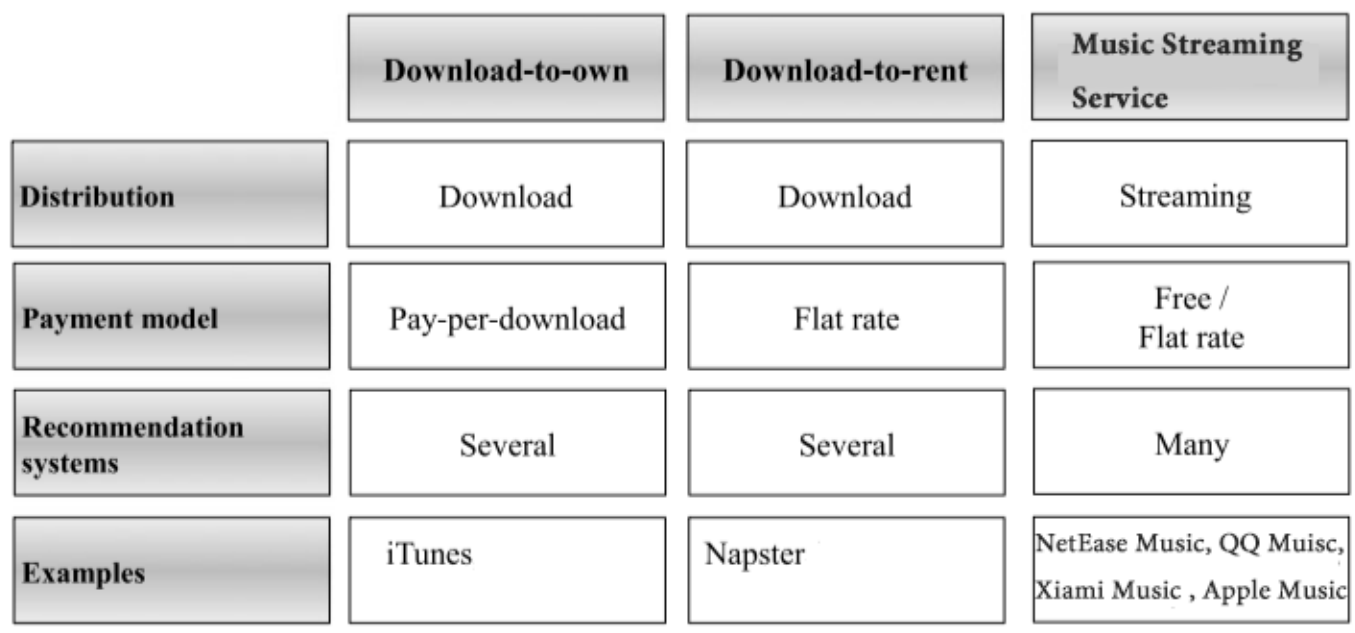

many other countries such as Japan and Germany where physical music product accounts for a large proportion of the market size, online music services based on information technologies dominate the market and call for more research to generate insights toward the management of music streaming information systems.

After that, consumers began to download music from the Internet and listen to music online with the maturity of Internet technology and digital music emergence. Simultaneously, digital music players were invented. According to Sanitnarathorn and Prajaknate (2018), Sony introduced the 'Walkman' in 1979 and also invented the MP3 digital format by its "Magic Gate Memory Stick" in 2002. Moreover, Apple also released the iPod in 2001, which can store 5 gigabytes of music or about 1,000 songs that could be easily downloaded from the Internet (Sanitnarathorn and Prajaknate, 2018). In recent years, the rapid development of smartphone technology like the Apple iPhone series and mobile network technologies such as 5G (the fifth generation of broadband cellular network technology) provides a hardware foundation for music streaming services (Ziegler et al., 2020). Moreover, emerging and popular music streaming services like Spotify, Apple Music, QQ Music (China) and NetEase Music (China) supported the software foundation. Streaming music refers to music streaming media continuously and simultaneously received by and delivered to a terminal user while running by an operator (Towse, 2020). The user can listen to music on the above music services before the entire file has been transmitted, which provides a more efficient and convenient approach to obtain music content.

Music consumer's ways of accessing and purchasing music are affected by the introduction of online music services and the increase in broadband speed (Martins and Slongo, 2014). Figure 1 displays the existing three digital music distribution transmissions on the Internet: download-to-own, download-to-rent and music streaming services. After 2000, the music industry started allowing digital music downloading through the Internet after a significant drop in revenue, known as download-toown consumption; download payments primarily expense that and originally be protected by Digital Rights Management System (DRMS) (Dörr et al., 2013). Although music can be transmitted into any terminal device without a validation program and can be disseminated without restrictions, the music still contains the information of its source on the music sharing website (Dörr et al., 2009). Moreover, download-to-rent consumption also adopted the digital rights management system (DRMS). Consequently, the music file downloaded on the users' terminal can only be played after the legal status test by DRMS. Lastly, the revenue model of music streaming services is recurring payments 
for the premium service subscription. During the subscription interval, consumers can access all the music without restrictions, while music streaming services are streaming music files to the user's devices. However, the music file is not permanently stored on the user's devices.

Usually, music streaming services adopt a "freemium" model, which provides premium services with subscription fees based on free use. Differently, music streaming ads such as Google or Amazon are not considered music streaming services because consumers purchase and download their own music and then update it to the cloud database of a service provider (Dörr et al., 2013). It is more advanced in the recommendation system in music streaming services, which means that users can easily share and receive music via mobile applications, email and social networks. Most music streaming services in China often provide a free service with advertising support, metered listening and a limited music library while promoting a premium monthly fee service that offers advertisingfree, unlimited access to music libraries and music offline playing allowance. Otherwise, there is still a unique market model like Apple music, which requires users to pay for subscriptions and then access the music library.

In China, owing to the large population base, the amount of Internet service users is higher than that of developed countries (Zhang et al., 2017). For example, although QQ Music only supports music streaming services in China, monthly user activity is up to 400 million higher than Spotify's 125 million and Deezer's 16 million (Zhang et al., 2017). However, the percentage of users who paid for premium music streaming services is 5 percent, which is lower than Spotify's 40 percent and Deezer's 37.5 percent (Zhang et al., 2017). Accordingly, huge potential with a giant user base but rare payment rate is an interesting phenomenon of the music streaming services market in China. Providing premium services is a major revenue model for most music streaming services providers; investigating the factors affecting this revenue model is significant. Research insights of the current study might also be generalized to the management of other online information systems that involve the co-existence of free and premium services.

\subsection{Existing Studies}

First of all, it is necessary to distinguish the two terminologies "digital music" and "streaming music" for a gap between them, and they have commonalities and nuances. Digital music is also known as digital sound recording or digital recording, a method of preserving sound (Campbell, 2015). Identically, streaming music is a digital sound uploaded in digital format and can be listened via music streaming services on the Internet. Precisely, the opposite word of streaming music is "downloading music", and they are different business models for digital music suppliers and different approaches to obtain digital music for listeners. Downloading music directly to store the music file in the user's own device after the user's one-time payment for a per song or per album means the downloaded music can be played without the Internet and transferred to other devices as the owner's willing. However, streaming music is different because the user does not actually own the tracks. The listener can subscribe to music streaming services over the Internet, either through Wi-Fi or mobile data and share the music library with other users.

According to Sinclair and Tinson (2016), music streaming service is a relatively new consumption pattern, particularly premium services and has not been completely studied in the marketing and consumer academic field. The previous research associated with understanding customers' intention in the music streaming service field can be divided into three types of theories, which are psychological, behavioral, and ethical theories. Firstly, the psychological ownership perspective was proposed by Belk (1988) and was employed by Pierce et al. (2003), Bartmanski and Woodward (2015) and Sinclair and Tinson (2016). Secondly, behavioral theory comprises the Theory of Reasoned Action (TRA) (Fishbein and Ajzen, 1975), the Theory of Planned Behavior (TPB) (Ajzen, 1991) and the Focus Theory of Normative Conduct (Cialdini, Kallgren and Reno, 1990). Much previous research concerning the digital or streaming music field has used behavioral theories above, such as Lin et al. (1999), Yoon (2010) and Sanitnarathorn and Prajaknate (2018). TRA and TPB intend to understand 
how individuals are influenced by intentions to involve behavior or activity. In addition to studies concerning music streaming, the theories of TRA and TPB is also well documented in studies investigating the consumption and adoption of other information systems by consumers. The theory of normative conduct is used to inspect the concept of human normative behavior. Thirdly, ethical theory mainly focuses on music piracy' influences on streaming music consumption. Normally, music piracy has negative influences on the music industry, including artists, record company and music streaming services. However, some researchers still claimed that the association between music piracy and streaming music service in China is paltry (Bai and Waldfogel, 2012).

\subsection{Research Question and Objective}

Music streaming services are consumer objects with potential and popularity in people's cultural needs and entertainment. Therefore, the discussion about the issues of premium music streaming services is full of practical significance. It can be observed that subscription-based online services are growing significantly worldwide. The current study could contribute to the Information System literature by providing insights into attracting more consumers with higher willingness-to-pay for the services. Additionally, few previous research pieces considered the premium music streaming services in China compared to other subjects about streaming music.

On the other hand, compared with the huge user base, the phenomenon of low premium services consumption rate in the music streaming industry partly reflects the transformation in the consumption patterns of Chinese digital music consumers is not equal to the economic growth stimulated by technological innovation. Consequently, it is meaningful to reveal the factors influencing the intentions of consumption in the music streaming services of China because the subscription of premium services is the central consumption approach for Chinese users in music streaming services.

Thus, this research is aimed to probe the factors affecting consumers' intention of the premium music streaming services' subscription in China. The research question is: what are the factors that influence consumers' intention of the premium music streaming services' subscription in China?

\subsection{Brief Summary of Proposed Research Method}

The research method will be an explanatory sequential mixed method provided by Creswell and Clark (2018), which indicates continuous collection and analysis of quantitative and qualitative data in two succeeding phases will be employed in this research. A quantitative perspective would be achieved by assembling the data, then study the association between object factors and others. The research data will be collected in the form of an online survey in China. The research model will propose an integrated model named the Theory of Streaming Service Acceptance (TSSA). There are four influencing factors, which are attitude (ATT), descriptive norm (DTN), injunctive norm (ITN) and perceived behavioral control $(P B C)$ and an affected factor intention (INT). The PLS (Partial Least Squares) - SEM (Structural Equation Modelling) is considered the primary approach for validating the current research model and the performance of the results. Additionally, SmartPLS 3.0 and SPSS are two statics analysis software providing data analysis of collected data.

In-depth interviews would reach a qualitative perspective to understand the individual's psychology or behavioral factors concerning the subscription intentions of music streaming services, which is appropriate to reveal the insights and depth needed to meet the research objective. An interview will be used to acquire authentic, meaningful and more subjective responses to explain the appearance of potential insignificant factors tested by a quantitative method. 


\section{LITERATURE REVIEW}

\subsection{The Business Model of Music Streaming Service}

The music streaming service with a subscription model emerged in previous years and continue to grow accompanying the network technology development. According to Arthur (2015), it is claimed that streaming media has some decisive strengths compared to downloading systems, such as massive music storage, convenient playlist sharing, easy to process of music discovery and ubiquitous music experience. The emergence of these music streaming services changed and attracted people who are unwilling to purchase downloads or physical CDs. Compared with downloads, in terms of revenue, the streaming performed better than downloads with an example of the percentage of the total digital revenue in Sweden in 2013, which shows that subscription of streaming owned 47 percent of revenue and downloads only had 7 percent (Guerra, 2015). Not surprisingly, more music streaming services emerge with such optimistic results and prospects.

However, the business model of music streaming services has sparked some controversy. Some researchers and music industry practitioners questioned this business model. They are dissatisfied with the free service level. Part of the record company indicated that physical and digital sales were being impaired by the "freemium" model (Guerra, 2015). Moreover, music streaming services can be viewed as a new radio, which is difficult to attract consumers' attention to purchase premium services, as suggested by Arthur (2015). On the other hand, some provided agreements on this business model. Streaming services are very beneficial for those artists who have built a solid catalog and are large on-site tours (Guerra, 2015).

Consequently, a deep understanding of the business model of music streaming serves is of great significance and necessity. In order to provide users with the music meeting their requirements, availability for streaming service is used. This requires music streaming services to negotiate with the appropriate record company (professional or independent) to license them. Additionally, the music premium services had to share a portion of its revenue with record providers as well as procure equity in the music streaming services.

\subsection{Theoretical Foundation of Theory of Streaming Service Acceptance}

Based on the existing theories or models that used to assess the human behaviors and the background of music streaming service, this paper proposes an integrated model called the Theory of Streaming Service Acceptance (TSSA), which can be used in the study of the streaming services, including the area of music. TSSA has four constructs that represent the determinants of users' intention of consumption in the streaming services. The four constructs are Attitude, Perceived Behavior Control, Descriptive Norm and Injunctive Norm.

The fundamental theories of the proposed theory consist of The Theory of Reasoned Action (TRA), The Theory of Planned Behavior (TPB), The Focus Theory of Normative Conduct and their expanded theories, including Decomposed Theory of Planned Behavior (DTPB), The Reasoned Action Approach (RRA), Unified Theory of Acceptance and Use of Technology (UTAUT), etc. Many behaviors of people in daily life can be considered under volitional behavior that they can lightly conduct these behaviors if they intend to do (Ajzen, 1985). For example, listen to music before bedtime, buy some drinks after dinner, watch a movie at an upscale theatre, or play a football match with friends. The theory of reasoned action (TRA) (Fishbein and Ajzen, 1975) is created to predict the volitional behavior of a human in everyday life and investigate their psychological determinant. According to Cesareo and Pastore (2014), some valuable knowledge and experience about premium music streaming services can be gained from TRA. Two primary factors are determining the intentions of TRA, from a personal aspect and social aspect. Conceptually, the personal factor, defined as an attitude, is the individual's positive or negative judgment of implementing the behavior (Fishbein and Ajzen, 1975). The social influence on a person's intention, defined as the subjective norm, is an individual's performance of the behavior determined by the perception of social pressures (Fishbein 
and Ajzen, 1975). In summary, people incline to perform behavior with their own positive judgment and with the approval of the people who are important to them.

TPB is an expansion of the TRA, which is proposed to solve the limitations of the original mode by Ajzen (1985). TRA indicates that the individual's intention is assumed as the main factor that grasps the motivational factors which can influence behavior, which means the stronger the intention to conduct a behavior, the higher possibility of its implementation (Ajzen, 1991). Nonetheless, the intention can only impact human behavior when the behavior is controlled by volition. Some criticisms were claimed by researchers on the TRA for the reason that it is not suitable to explain or predict the human behaviors of individuals with incomplete volitional control. Moreover, individuals' performances should be influenced by non-motivational factors like the existence of necessary resources and abilities such as skills, treasure, and knowledge (Ajzen, 1991). It is assumed by Ajzen (1991) that motivation and ability can mutually impact behavioral achievement. Therefore, the expected intentions should influence performance to the level that the individual has behavioral control. Performance should increase with behavioral control to the level that the individual is stimulated to try. For the purpose of overcoming this drawback of the TRA, Ajzen (1991) has made a significant development to the TRA by adding another construct, the perceived behavioral control, to the theoretical framework, which created the TPB.

The discipline of the focus theory of normative conduct has been extensively used for a long history by some researchers who view the concept as a significance to entirely realize human social behavior, such as Fishbein and Ajzen (1975), Berkowitz (1972) and McKirnan (1980), represented by Cialdini, Kallgren and Reno (1990). However, a debate about the interpretability and predictive value of normative norms in social psychology still existed. Cialdini, Kallgren and Reno (1990) noted that some researchers consider the concept ambiguous and exceedingly general, conflicting, and not suitable for empirical testing, such as Krebs and Miller (1985). In summary, both views are correct, which indicates that norms do strongly and regularly influence the behavior, but the power and form of that influence can only be reasonably determined through theoretical improvements that are traditional or strictly applied.

Norm can be referred either to what most people do or to what most people approve or disapprove of (Cialdini, Kallgren and Reno, 1990). Based on Deutsch and Gerard (1955), even though in the common circumstance, the confirmation that what other people usually do and confirm that others generally endorse and imply different motivations of human behavior. Therefore, with the given social group, social norms are divided into two parts, which are the norms that define the descriptive norms as the sensation of what is normal and the norms that define the injunctive norms as the sensation of what is socially sanctioned, claimed by Cialdini, Kallgren and Reno (1990).

Among the extensive version of TPB, the Reasoned Action Approach (RRA) is the latest and comprehensive model. The RRA divided the predictors, attitude, subjective norms and perceived behavioral control into pairs of sub-predictors (Fishbein and Ajzen, 2010). It divides the attitude into experiential and instrumental attitudes, subjective norms by injunctive and descriptive norms, and perceived behavioral control by capacity and autonomy. Following the focus theory of normative conduct (Cialdini, Kallgren and Reno, 1990), the RRA differentiates the injunctive and descriptive norms.

\subsection{Four Constructs of the TSSA and Hypotheses}

The research objective is to probe the factors affecting consumers' intention of the premium music streaming services' subscription in China. In order to achieve this, a research model is built as follows.

\subsubsection{Attitude}

According to Yoon (2010), Cesareo and Pastore (2014) and Dörr et al. (2013), attitude is a driving force used to forecast the individual's intention of performing behaviors in the music field, including 
music piracy, streaming music advertising and subscription-based music services. Based on these previous researches, attitude will be utilized as a construct in this research model.

The term attitude refers to an individual's position on a bipolar evaluative or effective dimension respecting some objects, actions, or events, and it also represents an individual's favorable or unfavorable feeling for certain stimulating objects. The construct is developed from several theories, including TRA, TPB, DTPB, ARR and UTAUT (Mohammad, 2015). According to Fishbein and Ajzen (1975), behavioral belief is defined as the abundant beliefs of a person about the outcome of behaviors. The strength of the beliefs predicts the possibility of one specific behavioral outcome and evaluates a possible behavioral outcome, impacting an individual's attitude to conduct the behavior. The outcome is bilateral. Hence, it is appropriate for this study to implement the attitude as a construct to investigate the effect of a person's intention of premium music streaming services' subscription.

Most previous studies addressing this subject implied that attitude was used for the study in intentions toward using music streaming services. In the study of Dörr et al. (2013), it is claimed that a favorable attitude to music streaming services positively affects a person's intention to use these services. Therefore, the following hypothesis is proposed:

H1: Attitude (ATT) toward premium music streaming services will influence a person's intention of the premium music streaming services' subscription.

\subsubsection{Descriptive Norm}

Descriptive norms motivate individuals by providing evidence of possible effective and adaptive actions (Cialdini, Kallgren and Reno, 1990). People can effectively perform an acceptable act by imitating the behavior of most people to a common extent. In this case, the sellers do not need to directly convince consumers that their products are good and just need to convince consumers that many others think.

Based on the proof of littering behavior (Geller et al., 1982), from a theoretical perspective, people are concerned about the environment in a chaotic environment faster than entering other clean environments. Therefore, the appropriate descriptive norms about littering will increase its positively normative behavior. In Köbis et al.'s (2015) study on the factors that influence corruption behavior, they found that the descriptive norms significantly affect corruption behavior. Corruption will be greatly reduced when descriptive norms against corruption are sent to the participants before conducting corruption actions. Additionally, descriptive norms may explain the interpersonal and cultural differences in corruption in reality. According to Reyes-Portillo et al. (2018), suicide ideation descriptive norms and suicide attempts to impact the incidence of adolescent suicidal ideation and lifelong suicide attempts. If a teenager believes that suicidal thoughts and suicidal attempts are common among his peers, he is more inclined to accept suicidal thoughts and attempts. Therefore, the descriptive norm is essential in studying human behavior and will be adopted as a construct to explore the current research target. Therefore, the following hypothesis is proposed:

H2: Descriptive norm (DTN) toward premium music streaming services will influence a person's intention of the premium music streaming services' subscription.

\subsubsection{Injunctive Norm}

The injunctive norm is the perception that most people endorse or disapprove in a social group, which is specified what ought to be done (Cialdini, Kallgren, and Reno, 1990). These injunctive norms motivate an individual's actions by promising social rewards and punishments. Therefore, one of the causes that people may remunerate our society is that it has been positively recognized in acting following the norms of social helpfulness (Berkowitz, 1972). Additionally, one of the reasons people 
can reward the received awards, favors, and benefits for complying with reciprocity guidelines is to gain social recognition and avoid social disapproval (Gouldner, 1960).

Similarly, based on the proof of littering behavior (Geller et al., 1982), the injunctive norm banned on littering led to a prohibited normative behavior, which decreased littering action. Therefore, the correct injunctive norms about littering will increase its positively normative behavior. Pedersen et al.'s (2017) research in the influence of peer alcohol use on youth drinking behavior found that while the descriptive alcohol norms affect a part of drinking outcomes, such as peak drinking, the injunctive alcohol norms affect all of the drinking outcomes. Therefore, injunctive alcohol norms may play a more significant role in prevention programs for youth drinking.

In this study, the injunctive norm will also be adopted as a construct to explore the positive effect of a person's intention to subscribe to music streaming services. Therefore, the following hypothesis is proposed:

H3: Injunctive norm (ITN) toward premium music streaming services will influence a person's intention of the premium music streaming services' subscription.

\subsubsection{Perceived Behavioral Control}

Perceived behavioral control is developed from TPB, DTPB, ARR and UTAUT. It describes the subjective perception difficulty of behavior. This includes external factors such as opportunities and time, and internal factors such as personal skills and property that meet the requirements of the object (Mohammad, 2015). Moreover, perceived behavioral control constitutes of two dimensions, namely the perceived power and the control belief. In detail, perceived power is the perception of the behavior or importance of these factors that may influence these factors, and control belief is individuals' perceptions of the promotion and impediment of specific behaviors. In this case, a person is more likely to make a subscription to a premium music streaming service if he or she perceived a great extent of control toward performing this action.

Xiao and Wang (2020) studied vaccine hesitancy regarding attitude, norms and perceived behavioral control. They targeted around 5200 participants and found that these three factors affect the vaccination intention, including perceived behavioral control. Vamvaka et al.'s (2020) research on entrepreneurial intention divided the predictor 'attitude' into instrumental attitude and affective attitude and the predictor 'perceived behavioral control' into perceived self-efficacy and perceived controllability. Results showed that affective attitude and perceived self-efficacy have a greater influence on entrepreneurial intention.

Additionally, this behavioral control has been adopted to portend the intention of music streaming service usage by Dörr et al. (2013) and the findings suggest that among attitude, subjective norms and perceived behavioral control, perceived behavioral control was the only predictor that is not significant. However, their research was conducted in German, while this research will be conducted in China. Therefore, this research will include the perceived behavioral control as a construct to evaluate its significance in this case. Therefore, the following hypothesis is proposed:

H4: Perceived behavioral control (PBC) toward premium music streaming services will influence a person's intention of the premium music streaming services' subscription.

Referring to all four hypotheses in Figure 2, which shows the relationship of each hypothesis of the theoretical structure proposed in the current research. 


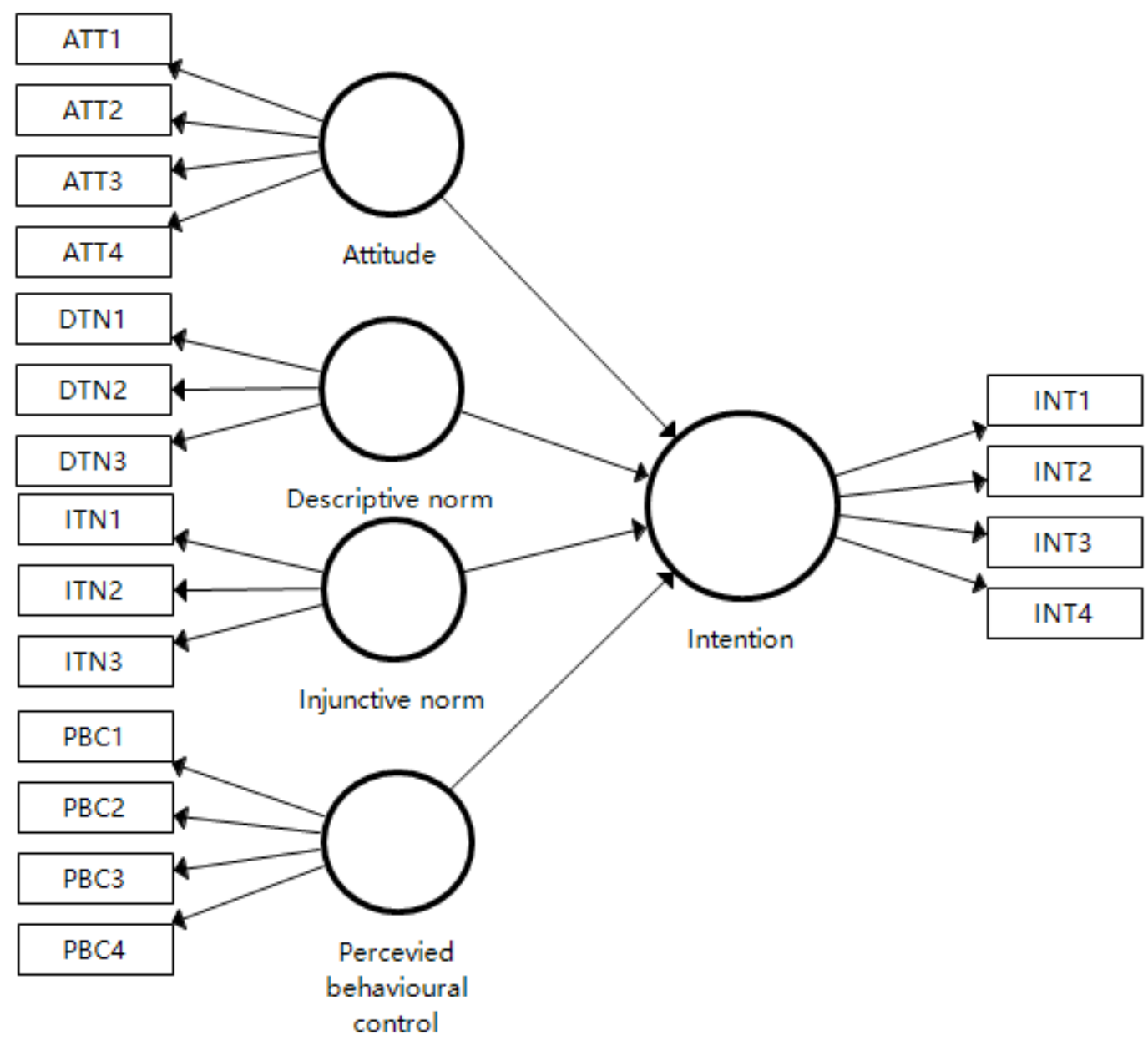

\section{RESEARCH METHODOLOGY AND RESULTS}

\subsection{The Explanatory Sequential Mixed Method}

According to Wolfe (2012), the emergence of this integrated methodology has gone through multiple stages of acceptance and improvement, which involves four strategic designs: triangulation, explanatory, exploratory, and embedded. Each design may be further adjusted by sequence, phases, and stages of research development and this research study incorporate explanatory sequential design.

Both quantitative and qualitative research methods have limits that may compromise an individual method study's strength (Wolfe, 2012). In a quantitative method, it is difficult to understand the background of the set responses clearly. Qualitative research provides contextual interviews consistent with quantitative research results, clarifying the research context and reducing or eliminating a single research weakness. Similarly, in a qualitative method, the study can influence the researcher's biases, which may be imposed on the interpretation of the respondent's interviews. To avoid that, adopting a quantitative component to the qualitative process and biases can be reduced through statistical evidence. Secondly, a mixed-method design supports using multiple data collection methods, which is comprehensive evidence provided by the dual data collection (Creswell and Clark, 2018). 
Thirdly, Creswell (2003) represents that the dual data collection promotes the researcher's ability to solve complex questions dynamically. Fourthly, the mixed-method study encourages researchers' collaboration and multidimensional thinking. Finally, the mixed method provides researchers with the freedom to utilize all possible strategies to solve problems.

This paper will use a two-phase process mixed method to collect evidence to understand the research objective. As Figure 3 shows, phase 1 is quantitative research, including quantitative data collection (online survey), quantitative data analysis (SPSS, PLS-SEM) and result evaluation. Phase 2 is qualitative research, including qualitative data collection (interview), qualitative data analysis (integration and refinement) and Overall finding and interpretation.

\subsection{Quantitative Research}

\subsubsection{Quantitative data collection and demographics}

The survey data was collected through an online questionnaire with the supports of WeChat software and the "WJX" website (https://www.wjX.cn). The link of the questionnaire was sent to all staff and students in one of the authors' university via the educational email. All the respondents voluntarily answered the questions and each question could be understood by respondents without leading questions in this online survey. There was an introduction at the beginning of the questionnaire explaining the purpose and the answer could be clearly guided straightforward. The reason why using the "WJX" website to construct an online survey is that it is rapid and convenient for sending interlink of the survey through popular social network applications (WeChat, QQ) in China. The respondents can easily participate in an online survey through the interlink in social network applications on their mobile devices. After the respondents finished the questions and clicked the submit button, the servicers will collect and preserve the data for output from the database.

214 people were responded to the survey questions. A part of respondents spent much less time than the average time consumption, which indicated that they might just cope with completing the questionnaire without seriously considering every question in the questionnaire. The data from this part of the respondents was not reliable. Thus, considering the accuracy and reliability of data, the system automatically filters the questionnaires that the time consumption of answering questions far below the average time consumption. In the end, $\mathrm{N}=120$ full valid samples were collected into the analysis process without loss of data.

SPSS 22 was used to implement the descriptive analysis. The demographic information of respondents includes 55 percent female $(n=66)$ and 45 percent male $(n=54)$ in Table 1 , which represents a nearly equal distribution between males and females of the sample. The participants' years old between 21 and 25 years old took the majority party, which was 53.3 percent $(n=64)$. Most of the respondents' education level was more than a Bachelor's degree, which consisted of 70 percent $(n=84)$ Bachelor's degree and 15 percent $(n=18)$ Master's degree and above. About 79.2 percent $(n=95)$ of the participants had the experience of subscribing to the premium music streaming services. The most acceptable monthly price range of premium music streaming services was 10 to $25 \mathrm{RMB}$, about 65.8 percent $(\mathrm{n}=79)$.

\subsubsection{Description of Questionnaire}

The questionnaire was conducted without revealing personal information. All answers to the items were measured by a seven-point Likert scale $(1=$ strongly disagree to 7 strong agree $)$. All questions refer to the guidance written by Ajzen (2006).

The attitude was measured by four items, such as "It is worthwhile to subscribe to the premium music streaming services."; "It is necessary to subscribe to the premium music streaming services."; "Using premium music streaming services could improve my music listening experience.";" Overall, my attitude toward premium music streaming services is favorable." (Ajzen, 2006). 
Phase I

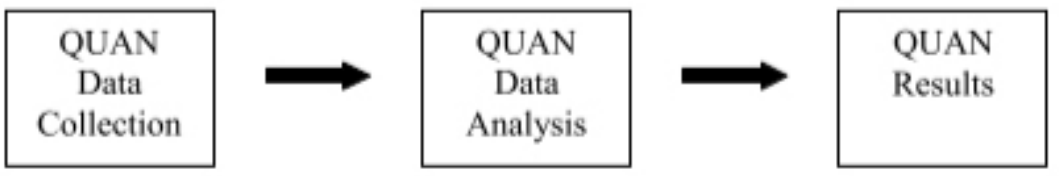

Data Collection

Data Analysis

\section{Results}

\section{Procedure}

Online survey

Likert scale (7 point)

Administer via web

\section{Product}

Mostly numeric data some qualitative data
Description analysis

Frequencies analysis

SPSS

Inspect trends
Summarize stats.

Charts \& tables

Demographics

Significant-non-

significant

Statistical results

\section{Descriptive \& Frequencies Report results in article Statistics, Emergence of trends}

Identify case study libraries and development interview questions to gather qualitative data to use to explain quantitative differences

Phase II

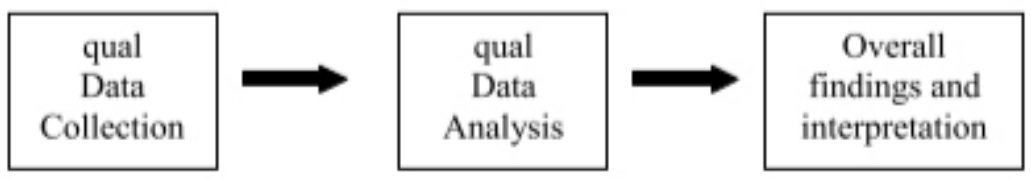

\section{Procedure}

One-on-one interviews and observations case study library 20 participants

\section{Product}

In depth rich Interview data Tapped
Read, transcribe, code data Develop \& interrelate themes Member checking \& peer review

Coded text, stories, and quotes

Individual voice

Similar \& different themes
Explain \& integrate insights QUAN and qual results

Compare \& discuss results Report findings in dissertation

Mixed method study is used to explain quantitative results through the gathering and analysis of qualitative data.

Descriptive norm was measured by three items, such as "Most of the people who are important to me are using premium services in streaming music platforms."; "Most of the people who are important to me have subscribed to multiple premium services on different streaming music platforms."; "Most of the people who are important to me are having good experiences in terms of using premium music streaming services." (Ajzen, 2006). 
Table 1. Sample demographics

\begin{tabular}{|l|l|l|l|}
\hline \multicolumn{1}{|c|}{ Demographic variables } & \multicolumn{1}{|c|}{ Item } & \multicolumn{1}{c|}{ Frequency } & \multicolumn{1}{c|}{ Percentage (\%) } \\
\hline Gender & Male & 54 & 45 \\
\hline & Female & 66 & 55 \\
\hline Age & 16 - 20 years old & 15 & 12.5 \\
\hline & 21 - 25 years old & 64 & 53.3 \\
\hline & 26 - 30 years old & 17 & 14.2 \\
\hline & $31-35$ years old & 12 & 10 \\
\hline & 36 - 40 years old & 12 & 10 \\
\hline Education level & High school and below & 4 & 3.3 \\
\hline & College degree & 14 & 11.7 \\
\hline & Bachelor's degree & 84 & 70 \\
\hline & Master's degree and above & 18 & 15 \\
\hline Experience & Subscribed & 95 & 79.2 \\
\hline & Not subscribed & 17 & 14.2 \\
\hline & No, but I intend to subscribe one. & 8 & 6.7 \\
\hline Acceptable price range (Monthly) & 10 RMB and below & 28 & 23.3 \\
\hline & 10 - 25 RMB & 79 & 65.8 \\
\hline & Above 25RMB & 13 & 10.8 \\
\hline
\end{tabular}

Injunctive norm was measured by three items, such as "Most of the people who are important to me think that I need to subscribe to the premium music streaming services."; "Most of the people who are important to me will persuade me to subscribe to the premium music streaming services if I have not subscribed to one."; "Most of the people who are important to me think that I should use premium music streaming services, even though this might be a little bit expensive." (Ajzen, 2006).

Perceived behavioral control was measured by four items, such as, "It is easy for me to operate the process of using premium music streaming services."; "I have the knowledge and ability to utilize and enjoy the contents of premium music streaming services if I subscribe to it."; "I can easily afford the fee of premium music streaming services."; "Overall, using premium music streaming services is completely within my control." (Ajzen, 2006).

The intention was measured by four items, such as "I intend to pay for premium music streaming services."; "I will frequently use premium music streaming services in the future."; "I will enjoy using the premium music streaming services."; "I will strongly recommend premium music streaming services to others." (Ajzen, 2006).

\subsubsection{Quantitative results}

The PLS (Partial Least Squares) - SEM (Structural Equation Modelling) model was accepted to validate the research model and perform the analysis result. PLS uses a component-based approach to estimating and sets minimal limitations on sample size and residual distributions (Yoon, 2010). PLS-SEM does not require a large sample size and normal distribution of the data compared with the traditional PLS method (Hair et al., 2017). Additionally, PLS-SEM was used to implement the presence of relatively thin sample sizes and exploratory level studies. SmartPLS 3.0 software was used to implement the analysis process. 
Table 2. Construct reliability and validity

\begin{tabular}{|l|l|l|l|l|}
\hline \multicolumn{1}{|c|}{ Construct } & Cronbach's Alpha & Composite Reliability & $\begin{array}{c}\text { Average Variance Extracted } \\
\text { (AVE) }\end{array}$ & Root of AVE \\
\hline ATT & 0.80 & 0.87 & 0.63 & 0.79 \\
\hline DSN & 0.87 & 0.92 & 0.79 & 0.89 \\
\hline ITN & 0.90 & 0.94 & 0.83 & 0.91 \\
\hline PBC & 0.86 & 0.90 & 0.70 & 0.84 \\
\hline INT & 0.89 & 0.93 & 0.76 & 0.87 \\
\hline
\end{tabular}

The process of quantitative analysis was divided into three stages. First, the PLS-SEM algorithm was implemented to evaluate the reliability and validity of the measurement items and the $\mathrm{R}^{2}$ value of the proposed theoretical framework. Second, the significance of the path coefficients was verified by the bootstrapping test. Moreover, the blindfolding test was implemented to examine the overall model fit with the $\mathrm{Q}^{2}$ value.

\subsection{Reliability and Validity of Measurement Items}

\subsubsection{Internal Consistency Reliability and Convergent Validity}

Cronbach's Alpha and Composite Reliability were used to examine the internal consistency reliability of the measurement items. However, Cronbach's alpha is limited by assuming that all indicators are equally reliable (tau-equivalence), which could seriously affect reliability (Raykov, 2007). On the contrary, composite reliability is more appropriate for PLS-SEM without considering tau-equivalence, prioritizing metrics based on their individual reliability (Hair et al., 2012). Referring to the structural equation models test guidelines proposed by Hair et al. (2012), the composite reliability of all the constructs should be no less than 0.70 .

Convergent validity was examined by Average Variance Extracted (AVE) and the AVEs should be greater than 0.50 . The results in Table 2 expressed that the constructs in this study have acceptable internal consistency reliability and convergence effectiveness whose composite reliabilities are greater than 0.85 and AVEs are greater than 0.60 .

\subsection{Discriminant Validity}

The discriminant validity of the measurement items was examined by the Fornell-Larcker criterion, the HTMT (Heterotrait-Monotrait) ratio and the cross-loadings of the indicators. Referring to Fornell and Larcker (1981), the root of AVEs of the constructs should be greater than the correlation with other constructs in the research model. Table 3 presents the result of the Fornell-Larcker criterion, the root of AVE of each latent construct is higher than the highest correlations with any other latent variables. For example, in PBC, the root of AVE of PBC is 0.836, which is greater than 0.743, 0.440, 0.626 and 0.584 .

According to Hair, Ringle and Sarstedt (2011), an indicator's loadings should be higher than all of its cross-loadings. Table 4 shows that all indicators show higher loadings with their respective constructs than with the other constructs. For example, the DNS1 has the highest loading (0.906) with its own constructs (DTN) compared with ATT (0.489), ITN (0,585), INT (0.641) and PBC (0.598).

As suggested, the HTMT ratio of all constructs should below 0.90 applying a permissive criterion (Gold, Malhotra and Segars, 2001; Teo, Srivastava and Jiang, 2008). The HTMT ratio result was shown in Table 5, indicating that all value is below 0.90 .

Based on these three measurements, it indicates that discriminant validity is established on the construct level. 
Table 3. Fornell-Larcker criterion

\begin{tabular}{|l|l|l|l|l|l|}
\hline \multicolumn{1}{|c|}{ Construct } & \multicolumn{1}{c|}{ ATT } & \multicolumn{1}{c|}{ DSN } & \multicolumn{1}{c|}{ ITN } & PBC & INT \\
\hline ATT & 0.79 & & & & \\
\hline DSN & 0.63 & 0.89 & & & \\
\hline ITN & 0.60 & 0.73 & 0.91 & & \\
\hline PBC & 0.58 & 0.63 & 0.44 & 0.84 & \\
\hline INT & 0.71 & 0.73 & 0.64 & 0.74 & 0.87 \\
\hline
\end{tabular}

Table 4. The cross-loading of indicators

\begin{tabular}{|c|c|c|c|c|c|}
\hline & ATT & DTN & ITN & PBC & INT \\
\hline ATT1 & 0.86 & 0.49 & 0.45 & 0.51 & 0.65 \\
\hline ATT2 & 0.67 & 0.36 & 0.41 & 0.32 & 0.38 \\
\hline ATT3 & 0.76 & 0.67 & 0.59 & 0.46 & 0.54 \\
\hline ATT4 & 0.87 & 0.48 & 0.46 & 0.52 & 0.64 \\
\hline DTN1 & 0.49 & 0.91 & 0.59 & 0.60 & 0.64 \\
\hline DTN2 & 0.47 & 0.90 & 0.60 & 0.55 & 0.64 \\
\hline DTN3 & 0.71 & 0.86 & 0.75 & 0.52 & 0.67 \\
\hline ITN1 & 0.63 & 0.69 & 0.92 & 0.47 & 0.66 \\
\hline ITN2 & 0.52 & 0.66 & 0.92 & 0.35 & 0.53 \\
\hline ITN3 & 0.47 & 0.64 & 0.90 & 0.36 & 0.55 \\
\hline PBC1 & 0.48 & 0.56 & 0.41 & 0.83 & 0.66 \\
\hline PBC2 & 0.58 & 0.50 & 0.38 & 0.85 & 0.59 \\
\hline PBC3 & 0.43 & 0.48 & 0.27 & 0.81 & 0.56 \\
\hline PBC4 & 0.46 & 0.54 & 0.40 & 0.85 & 0.66 \\
\hline INT1 & 0.60 & 0.58 & 0.48 & 0.66 & 0.88 \\
\hline INT2 & 0.64 & 0.65 & 0.55 & 0.73 & 0.89 \\
\hline INT3 & 0.55 & 0.64 & 0.45 & 0.70 & 0.87 \\
\hline INT4 & 0.69 & 0.68 & 0.76 & 0.49 & 0.83 \\
\hline
\end{tabular}

Table 5 Heterotrait-Monotrait ratio

\begin{tabular}{|l|l|l|l|l|l|}
\hline & \multicolumn{1}{|c|}{ ATT } & \multicolumn{1}{c|}{ DTN } & ITN & PBC & INT \\
\hline ATT & & & & & \\
\hline DTN & 0.77 & & & & \\
\hline ITN & 0.69 & 0.82 & & & \\
\hline PBC & 0.71 & 0.72 & 0.49 & & \\
\hline INT & 0.86 & 0.83 & 0.71 & 0.84 & \\
\hline
\end{tabular}




\begin{tabular}{|l|l|l|l|l|l|l|}
\hline & $\begin{array}{c}\text { Original } \\
\text { Sample } \\
(\mathbf{O})\end{array}$ & $\begin{array}{c}\text { Sample } \\
\text { Mean(M) }\end{array}$ & $\begin{array}{c}\text { Standard } \\
\text { Deviation(STDEV) }\end{array}$ & $\begin{array}{c}\text { T } \\
\text { Statistics(IO/ } \\
\text { STDEVI) }\end{array}$ & P Value & Hypothesis Testing \\
\hline ATT -> INT & 0.26 & 0.27 & 0.09 & 2.92 & 0.00 & H1, supported \\
\hline DTN -> INT & 0.19 & 0.17 & 0.11 & 1.83 & 0.07 & H2, not supported \\
\hline ITN -> INT & 0.18 & 0.19 & 0.09 & 2.07 & 0.04 & H3, supported \\
\hline PBC -> INT & 0.39 & 0.39 & 0.09 & 4.52 & 0.00 & H4, supported \\
\hline
\end{tabular}

\subsection{Hypotheses Testing}

Through the implementation of the bootstrapping algorithm, these four hypotheses were tested by the significance of the path coefficients and P-value, whose results are represented by Table 6.

Depended on bootstrapping results, Hypothesis 1, 3, and 4 are supported. For explanation, the subsample of the bootstrapping algorithm is 5000, with a significance level of 0.05 . Moreover, the P-values of H1 (0.004), H3 (0.039) and 4 (0.000) are less than 0.05. Therefore, these three hypotheses illustrate the relationships between constructs, which indicates that a person's attitude (ATT), injunctive norm (ITN) and perceived behavioral control (PBC) in terms of premium music streaming services were significantly and positively associated with his or her intention of premium music streaming services' subscription. However, the P-value of $\mathrm{H} 2$ is 0.068 , which is greater than 0.05 , making it a not supported hypothesis.

First, the result of Hypothesis 1 shows that if a person forms a positive or favorable attitude toward premium music streaming services, he or she would perceive that subscribing to the premium music streaming services would positively influence his or her music experience. Second, the result of Hypothesis 4 shows that if a person both owns mental ability and technical equipment for using the services, he or she will attempt to accept these premium services for a better music experience.

Third, the result of Hypothesis 2 cannot be supported. One potential explanation is that in the process of acquiring the descriptive information about subscribing to premium music streaming services of the people who are important to respondents, the individuals could understand the meaning of descriptive norm but could not summarize whether it can improve their music experience. Moreover, the behavioral intention about music streaming service could be a subjective assessment of an individual, which requires a subjective method (e.g., interview) to analyze it. Finally, the result of Hypothesis 3 expresses that the injunctive norm motivates a person to subscribe to the premium music streaming services with positive identification and social rewards.

\subsection{Examination of Structural Model}

The overall model fit was performed by $\mathrm{R}^{2}$ value, calculated by the PLS-SEM algorithm and $\mathrm{Q}^{2}$ value, which was produced by the blindfold algorithm. Referring to Hair, Ringle and Sarstedt (2011), $\mathrm{R}^{2}$ values of the endogenous latent variables in the structural model are $0.75,0.50$, or 0.25 , respectively, which can be described as substantial, medium, or weak. Moreover,

Q2 values greater than $0,0.25$ and 0.50 depict small, medium and large predictive relevance to the endogenous construct under consideration (Hair, Ringle and Sarstedt, 2011). Table 7 shows that the $\mathrm{R}^{2}$ value of intention is 0.731 between 0.5 and 0.75 , making a medium structural model. The $\mathrm{Q}^{2}$ value of intention is 0.509 , which demonstrates an overall good fit.

In summary, the results of quantitative research indicate that the research model constructs are reliable and valid. Simultaneously, the test of hypotheses represents three factors, including attitude, injunctive norm and perceived behavioral control, without the non-significant factor descriptive norm, which are positively associated with consumers' intention of premium streaming music services' 
Table 7. Overlapping of facet cross-validation and $\mathbf{R}^{2}$

\begin{tabular}{|l|l|l|l|}
\hline & \multicolumn{1}{|c|}{$\mathbf{Q}^{2}$} & \multicolumn{1}{c|}{$\mathbf{R}^{2}$} & \multicolumn{1}{c|}{${\text { Adjusted } \mathbf{R}^{2}}^{2}$} \\
\hline INT & 0.51 & 0.73 & 0.72 \\
\hline
\end{tabular}

subscription. Therefore, qualitative research will be used to investigate and reveal the reason why descriptive norm is a non-significant determinant.

\subsection{Qualitative Research}

\subsubsection{Qualitative Data Collection}

In order to explain why descriptive norm is not a significant factor that affects a person's intention of subscribing to the premium music streaming services, a qualitative study was processed to find some subjective factors causing this result.

As for the qualitative data collection, an interview-based on Hypothesis 2's unsupported result will be processed within 20 respondents who have participated in the online questionnaire survey before. The data was collected from two sources to provide the richness and the depth of each case description and included face-to-face interviews with participants; online interviews through the instant message application (Wechat).

\subsubsection{Description and result of interview questions}

There were three themes that emerged from a careful review of the quantitative results related to the descriptive norm.

\subsubsection{1. "If you only know that most people who are important to you are using or have used premium music streaming services (you are not being persuaded to subscribe), will this prompt you to subscribe to these services? Why?"}

Above half of the respondents' answer $(n=15)$ is "No" and there are several keywords of their explanation: (1) "No interest in music", (2) "Against conformity behavior", (3) "Rational consumption concept", and (4) "High subscription fee". First, "No interest in music" means that the music is not a primary interest for the respondents who may consume other products (video games, photography) instead of music products. Second, "Against conformity behavior" regarding the social psychology field may indicate the rise of independent thinking in young consumers. Third, the "Rational consumption concept" and "High subscription fee" can be viewed as an embodiment of moderate consumption, which means that the respondents did not intend to consume unnecessary and exceeding consumption levels products.

The rest of the respondents' answer $(\mathrm{n}=5)$ is "Yes," and the keywords of their explanation are: "Social interaction requirement" and "It is cheap to have a try". First, "Social interaction requirement" provides that music streaming services is a social interaction requirement of a part of consumers who could be easily influenced by peers. It is called the peer effect, which is defined as a special kind of network externality, a spillover effect caused by peers and their social background and a series of behaviors and attitudes of peers (Song and Yang, 2016). Second, "It is cheap to have a try" shows that income level is still an essential factor influencing consumption.

3.7.2.2. "There are two factors that (1) you know most people who are important to you are using or have used premium streaming music services (descriptive norm), and (2) you are persuaded to subscribe to premium streaming music services by most people who are important to you (injunctive norm). Which one is more likely to affect your intention to subscribe to these services? Why?"

Above half of the respondents $(n=14)$ indicated that they would intend to subscribe to the premium music streaming services with a greater probability of being persuaded to subscribe to these services. 
In general, injunctive norms (what should do) is more easily affect a person's intention to endorse the services in responding to trust and friendship with friends or families. For example, a respondent answered, "Because people who are important to me highly recommend it, which means this service gives them incredible satisfaction and an unparalleled experience. I trust my friends, so I will try to subscribe to get first-hand information." On the contrary, the descriptive norm (what is doing) cannot effectively change the existing attitude toward an object. For example, "The former factor (descriptive norm) does not affect my judgment of my own needs." Also, an individual's conformity behavior can be more easily stimulated by the injunctive norm but the descriptive norm. For example, "Very important people persuade to be more likely to influence because I am a person without opinion" and "I am a person who can easily follow the trend."

\subsubsection{3. "What do you think of why only knowing that most people who are important to you are using or have used premium streaming music services cannot efficiently affect your intention toward subscribing to these services?"}

Similarly, the outcome of this question expresses the respondents' rational consumption concept, the mention that against conformity behavior and personal interests. Giving the representative examples, "Because I think this is a thing with a personal interest and a preference. I feel that if there is no friend to recommend it to me, it means that my friend may think the services not be suitable for me or he does not want me to pay for a subscription" and "Subscribing to these services is a matter of personal preference. Each of these preferences is different because it is not reasonable to buy someone else unless it is something that can show off, making people have an affinity with the surrounding people." These answers are highly consistent with the above reasons.

\section{OVERALL INTERPRETATION AND EVALUATION}

The study provides a comprehensive understanding of a music consumer's intention to subscribe to the premium music streaming services (i.e., an online music consumption information system facilitated by technological advancements) by providing an integrated model. With the quantitative study of a sample including 120 respondents, the findings disclosed that all the constructs included in the research model except descriptive norm are significant predictors for the intention to subscribe to the premium music streaming services. By conducting the following qualitative research of a sample, including 20 participants of quantitative research, the study also provides a subjective interpretation for the no significance of descriptive norm.

\subsection{The Significance of Descriptive and Injunctive Norms on Consumer's Intention of the Music Streaming Services' Subscription}

The current research contributes to the model for studying the consumer's intention of the music streaming services' subscription from two aspects. First, the theoretical framework this paper provided separates subjective norms into the descriptive norm and injunctive norm in the study of intention towards online services. Although previous research has discussed the influence of descriptive norm and injunctive norm on the user intention, these studies mainly focused on health instead of consumers' intention towards products or services. For example, Dörr et al. (2013) have examined the effect of subjective norms on the intention to use music streaming services. Second, the current research found that the injunctive norm has a more effective impact on an individual's intention toward subscribing to the premium music streaming services than the descriptive norm. Thus, people's intentions toward premium music streaming music services are susceptible to social interaction and interpersonal relationships. Meanwhile, people have a certain sense of rational consumption and anticonformity behavior, which means they intend to consume products that satisfy their own interests and consumption extents. This result delivers important practical implications from the perspective of music streaming services providers, and potentially, to the management of other information systems 
for consumers' online consumption. Music streaming services can offer more convenient and rich social interaction content in premium services, such as massage function, sharing function. Additionally, more diversified and specialized content should be added to the premium services for consumers. For example, different music types can be divided into different, more detailed professional sections with music recommendations, music articles and musicians' introduction.

\subsection{The Effectiveness of the Theoretical Framework in Explaining the Consumers' Intention of the Premium Music Streaming Services' Subscription}

Another contribution of the current research is that the study area was focused on the specific area of premium music. Previous research only has considered the intentions toward using music streaming services (e.g., Dörr et al., 2013) or toward music piracy (Yoon, 2010) adopted the TPB. Attitude and perceived behavioral control are defined as two significant predictors for a person's intention to subscribing to the premium music streaming services. Therefore, a positive attitude toward a premium music streaming service could enhance a person's intention to subscribe to this service. According to Fishbein and Ajzen (1975), because the attitude is determined by salient beliefs that can be replaced by new beliefs, a person's negative attitude toward subscribing to premium music streaming services could be replaced by a positive attitude. Moreover, less subjectively perceived difficulty of subscribing to a premium music streaming service could promote a person's intention to subscribe to this service.

\subsection{Practical Implications}

This outcome also has important practical implications from the perspective of music streaming services providers. The premium services should be designed to meet the requirements of most consumers, such as reasonable prices, abundant content for transmitting a positive impact on consumers. Some promotions and content upgrades of premium services could be accepted to change people's existing negative attitudes toward the services. Moreover, increasing the ease of use and decreasing the threshold for subscribing to the premium music streaming services are rational suggestions for music streaming services suppliers. Given the findings of the current study, we found a significant relationship between injunctive norms and premium music service subscription intentions. Therefore, when designing and implementing marketing activities to encourage the adoption of paid streaming services, it is beneficial for marketers to use injunctive norm-based messages rather than those based on descriptive norms.

In addition to the applications of research findings in the music streaming industry, the findings of the current study also provide useful insights into other industries that adopt similar business models. For example, for the online services that involve membership programs such as Amazon Prime service, Apple Music subscription, Netflix's membership, the research findings of the current study could also be considered while designing and delivering marketing or promotional campaigns to attract more consumers. However, more research is needed to test the generalizability of the research findings.

\section{CONCLUSION AND LIMITATION}

The current research discovers the antecedents of an individual's intentions of the premium music streaming services' subscription under the existing theories used to assess the human behaviors and the service itself. An explanatory sequential mixed method, including quantitative research and qualitative research, was adopted in analyzing the search objective. The 120 quantitative data was processed by the PLS-SEM technique, and then the 20 qualitative data from the participants of the previous online survey was collected by an interview. Afterward, the research purpose is to complete the research blank and enhance the music experience for customers by assessing the effect of attitude (ATT), descriptive norm (DTN), descriptive norm (DTN) and perceived behavioral control (PBC) on people's intentions to subscribe to a premium service. The outcomes of the current study promote 
our understanding of people's behavioral intentions of subscribing to a premium service to advance their music experience.

In detail, the research outcome revealed that a person's descriptive norm could not effectively affect their intention to subscribe to the premium music streaming services. A person's positive attitude would contribute to higher using intentions to the premium music streaming services; an individual's injunctive norm and perceived behavioral control had a positive impact on his or her subscription intention. Besides, some subjective and psychological factors have influences on people's descriptive norms and injunctive norms. A person's rational consumption concept and anti-conformity behavior could negatively affect a person's descriptive norm, decreasing his or her subscription intention. On the contrary, a person's social interaction requirements and interpersonal relationships could positively impact a person's injunctive norm, contributing to increasing his or her subscription intention. There are relevant theoretical contributions in understanding social behaviors and practical indications in subscription intentions toward premium music streaming services. The streaming business has huge potential. According to Khandelwal (2019), nearly $25 \%$ of US households will drop the traditional cord-based cable by 2022. Additionally, streaming media has various forms, including movies, TV shows, music, video games, and more. Our research findings can be applied to the premium music streaming services and other streaming business outlined above.

However, there still exist limitations of the current study. First, most of the survey participants were between the ages of 20 and 30, and the education level of Bachelor's degree and above. Thus, more empirical research with a diversified sample is required to verify the generalizability of the current results and the applicability of the established theoretical framework. For example, more cover the respondents' age of 15 and 20 and high school and college education. Moreover, the methodology limitations are that there are no goodness-of-fit indices such as chi-square in the method of PLS-SEM and the size of our research sample is relatively small. Our future research will adjust our method and enrich the data to make our results more accurate and comprehensive. Last, current research cannot solve some specific questions, such as what factors affect a person's attitude toward subscribing to premium music streaming services, and what objective factors influence that a person's descriptive norm is not a significant predictor of his or her subscription intention on premium music services. In the future research, it may discuss deeper into the objective reasons affecting a person's descriptive norm and consider the relationship between descriptive norm and injunctive norm in a relevant topic, and social and psychological factors influencing a person's attitude toward his or her intention in related research to give more reasonable interpretations of the results.

\section{ACKNOWLEDGMENT}

This research is partly supported by VC Research (VCR 0000123) for Prof. Chang. 


\section{REFERENCES}

Ajzen, I. (1985). From intentions to actions: A theory of planned behavior. In J. Kuhl \& J. Beckman (Eds.), Action-control: From cognition to behavior (pp. 11-39). Springer. doi:10.1007/978-3-642-69746-3_2

Ajzen, I. (1991). The theory of planned behavior. Organizational Behavior and Human Decision Processes, 50(2), 179-211. doi:10.1016/0749-5978(91)90020-T

Ajzen, I. (2002). Attitudes. In R. Fernandez Ballesteros (Ed.), Encyclopedia of psychological assessment (Vol. 1, pp. 110-115). Sage Publications.

Ajzen, I. (2005). Attitudes, personality, and behavior (2nd ed.). Milton-Keynes, UK: Open University Press, McGraw-Hill.

Ajzen, I. (2006). Constructing a Theory of Planned Behavior Questionnaire. Available at: https://people.umass. edu/aizen/pdf/tpb.measurement.pdf

Ajzen, I. (2011). The theory of planned behavior: Reactions and reflections. Psychology \& Health, 26(9), 1113-1127. doi:10.1080/08870446.2011.613995 PMID:21929476

Ajzen, I., \& Fishbein, M. (1980). Understanding attitudes and predicting social behavior. Prentice-Hall.

Arthur, C. (2015). Streaming: the future of the music industry, or its nightmare? The Guardian. https://www. theguardian.com/technology/2015/jan/02/streaming-music-industry-apple-google

Bai, J., \& Waldfogel, J. (2012). Movie piracy and sales displacement in two samples of Chinese consumers. Information Economics and Policy, 24(3), 187-196. 10.1016/j.infoecopol.2012.08.002

Bartmanski, D., \& Woodward, I. (2015). Vinyl: The analogue record in the digital age. Bloomsbury Publishing. doi:10.1086/666376

Belk, R. (1988). Possessions and the extended self. Journal of Consumer Research, 15(1), 139-168. Available from: http://refhub.elsevier.com/S0148-2963(16)30571-9/rf0015

Berkowitz, L. (1972). Social norms, feelings, and other factors affecting helping and altruism. In L. Berkowitz (Ed.), Advances in experimental social psychology (Vol. 6). Academic Press. doi:10.1016/S0065-2601(08)600258

Berlin Dörr, J., Benlian, A., Grau, C., \& Wilde, T. (2009) Music distribution ohne Digital Rights Management Eine empirische Analyse der Lock-in- und Netzeffekte in Ecosystem iTunes. Proceedings of the 9th international conference Wirtschaftsinformatik, 9.

Campbell, J. (2015). Digital Sound Recording. Salem Press Encyclopedia of Science. Available from: http:// search.ebscohost.com.ez.xjtlu.edu.cn/login.aspx?direct=trueanddb=ersandAN=87995239andsite=eds-live

Cesareo, L., \& Pastore, A. (2014). Consumers' attitude and behavior towards online music piracy and subscriptionbased services. Journal of Consumer Marketing, 31(6/7), 515-525. doi:10.1108/JCM-07-2014-1070

Cialdini, R. B., Reno, R. R., \& Kallgren, C. A. (1990). A focus theory of normative conduct: Recycling the concept of norms to reduce littering in public places. Journal of Personality and Social Psychology, 58(6), 1015-1026. doi:10.1037/0022-3514.58.6.1015

Creswell, J. W. (2003). Research design qualitative, quantitative, and mixed methods approaches (2nd ed.). Sage Publications Inc.

Creswell, J. W., \& Plano Clark, V. L. (2018). Designing and conducting mixed methods research. Sage Publications Inc.

Deutsch, M., \& Gerard, H. B. (1955). A study of nonnative and informational social influence upon individual judgment. Journal of Abnormal and Social Psychology, 51, 629-636.

Dörr, J., Wagner, T., Benlian, A., \& Hess, T. (2013). Music as a Service as an Alternative to Music Piracy? An Empirical Investigation of the Intention to Use Music Streaming Services. Wirtschaftsinformatik. Advance online publication. doi:10.1007/ s11576-013-0387-x 
Fishbein, M. (1963). An investigation of the relationships between beliefs about an object and the attitude toward that object. Human Relations, 16, 233-239.

Fishbein, M., \& Ajzen, I. (1975). Belief, Attitude, Intention and Behavior: An Introduction to Theory and Research. Addison-Wesley.

Fornell, C., \& Larcker, D. F. (1981). Evaluating structural equation models with unobservable variables and measurements error. JMR, Journal of Marketing Research, 18(4), 39-50. doi:10.1177/002224378101800104

Geller, E. S., Winett, S., \& Everett, P. B. (1982). Preserving the environment. Pergamon.

Gold, A., Malhotra, A., \& Segars, A. (2001). Knowledge Management: An Organizational Capabilities Perspective. Journal of Management Information Systems, 18, 185-214.

Gouldner, A. W. (1960). The norm of reciprocity: A preliminary statement. American Sociological Review, $25,161-178$.

Hair, J. F., Hult, G. T. M., Ringle, C. M., \& Sarstedt, M. (2017). A primer on partial least squares structural equation modelling (PLS-SEM). Sage Publications, Inc. Retrieved from https://liverpool.idm.oclc.org/ login?url=http://search.ebscohost.com/login.aspx?direct=true \&db=cat00003a \&AN=lvp.b5097371\&site=edslive \&scope $=$ site

Hair, J. F., Ringle, C. M., \& Sarstedt, M. (2011). PLS-SEM: Indeed a Silver Bullet. Journal of Marketing Theory and Practice, 19(2), 139-152.

Hair, J. F., Sarstedt, M., Ringle, C. M., \& Mena, J. A. (2012). An assessment of the use of partial least squares structural equation modelling in marketing research. Journal of the Academy of Marketing Science, 40(3), 414-433. doi:10.1007/s11747-011-0261-6

João Constantino Torres Macedo Guerra. (2015). Purchase Intention on Online Content Services: An Application to the Music Streaming Services. Available at: $\mathrm{http}$ ://search.ebscohost.com/login.aspx?direct=trueanddb=edsrc aandAN=rcaap.com.UP.10216.80145andsite $=$ eds-liveandscope $=$ site

Khandelwal, R. (2020). An Overview of the Streaming Services Industry. Available at: https://marketrealist. com/2019/09/an-overview-of-the-streaming-services-industry/

Köbis, N. C., van Prooijen, J. W., Righetti, F., \& Van Lange, P. A. (2015). "Who Doesn't?" The Impact of Descriptive Norms on Corruption. PLoS One, 10(6), e0131830. https://doi.org/10.1371/journal.pone.0131830

Kostova, Dirks, \& Olin. (2002). The State of Psychological Ownership: Integrating and Extending a Century of Research. Review of General Psychology, 7. Available from: https://www.researchgate.net/publication/228688296_ The_State_of_Psychological_Ownership_Integrating_and_Extending_a_Century_of_ResearchKrebs, D. L. (1970). Altruism: An examination of the concept and a review of the literature. Psychological Bulletin, 73, 258-302.

Krebs, D. L., \& Miller, D. T. (1985). Altruism and aggression. In G. Lindzey \& E. Aronson (Eds.), The handbook of social psychology (3rd ed.). Random House.

Lin, T. C., Hsu, M. H., Kuo, F. Y., \& Sun, P. C. (1999). An Intention Model-Based Study of Software Piracy. Proceedings of the 32nd Hawaii International, Conference on System Sciences.

Mander, G. (1967). Verbal learning. In T. M. Newcomb (Ed.), New Directions in Psychology (Vol. 3, pp. 1-50). Holt.

McKiman, D. J. (1980). The conceptualization of deviance: A conceptualization and initial test of a model of social norms. European Journal of Social Psychology, 10, 79-93.

Paulo Capelli Martins, J., \& Antonio Slongo, L. (2014). The Digital Music Market: A study of Brazilian consumers' behavior. Revista Brasileira de Gestão de Negócios, 16(53), 638-657. doi:10.7819/rbgn.v16i52.1487

Pedersen, E. R., Osilla, K. C., Miles, J. N., Tucker, J. S., Ewing, B. A., Shih, R. A., \& D’Amico, E. J. (2017). The role of perceived injunctive alcohol norms in adolescent drinking behavior. Addictive Behaviors, 67, 1-7. https://doi.org/10.1016/j.addbeh.2016.11.022 
Raykov, T. (2007). Reliability if deleted, not 'alpha if deleted': Evaluation of scale reliability following component deletion. British Journal of Mathematical \& Statistical Psychology, 60, 201-216. doi:10.1348/000711006X115954

Reyes-Portillo, J. A., Lake, A. M., Kleinman, M., \& Gould, M. S. (2018). The Relation between Descriptive Norms, Suicide Ideation, and Suicide Attempts among Adolescents. Suicide \& Life-Threatening Behavior. Advance online publication. doi:10.1111/sltb.12446

Sinclair, G., \& Tinson, J. (2017). Psychological ownership and music streaming consumption. Journal of Business Research, 71, 1-9. 10.1016/j.jbusres.2016.10.002

Song, J. H., \& Yang, X. Y. (2016). A study of Undergraduates' Consumption Status and Promotion of Rational Consumption in Hebei Province. Journal of Hebei University of Science and Technology, 16(4). Advance online publication. doi:10.3969/j.issn.167-1653.2016.04.014

Teo, T. S. H., Srivastava, S. C., \& Jiang, L. (2008). Trust and Electronic Government Success: An Empirical Study. Journal of Management Information Systems, 25(3), 99-132.

Towse, R. (2020). Dealing with digital: the economic organisation of streamed music. Media, Culture and Society. 10.1177/0163443720919376

Vamvaka, V., Stoforos, C., \& Palaskas, T. (2020). Attitude toward entrepreneurship, perceived behavioral control, and entrepreneurial intention: Dimensionality, structural relationships, and gender differences. J Innov Entrep, 9, 5. https://doi.org/10.1186

Wolfe, J. A. (2012). Navigating the gatekeepers: A mixed method study of early career librarians in the tenure process. Available at: http://search.ebscohost.com/login.aspx?direct=trueanddb=cat04589aandAN=xlu. AAI3504005andsite $=$ eds-liveandscope $=$ site

Zhang, F., Mao, Q., Liu, E., Liu, Y., \& Xu, H. (2017). China Digital Music Market Development Report in 2017. Available from: http://www.199it.com/archives/631666.html

Ziegler, C., Neudel, R., Pham, S., \& Troudt, E. (2020). Improving media streaming services for train passengers with 5G. In IMX '20: ACM International Conference on Interactive Media Experiences. ACM. https://doi. org/10.1145/3391614.3399399. 


\section{APPENDIX A. SURVEY}

\section{A Short Interview Summary for Those Not Supporting Paying for Music}

No. The reason is that everyone has different needs and love for music, some people, such as me, are satisfied with music products that are provided for free. I don't need this service, so even if I know they have purchased it, it cannot be my consumption motivation. Besides, I am a poor girl. I can't listen to music asking for money! So people with different financial situations can't just buy it just because people around them are using it, right?

No. The reason is that I think it's this I am not a follower person, so if I don't see this thing that has been of great help to my friends, I will not subscribe to others, unless he strongly recommends me, I will consider it.

No. The paid service supports multiple users sharing services through one account.

No. Because I have no money.

No, because I haven't understood the specific benefits of membership. If you don't know the advantages of membership and the difference between not buying a membership, you won't buy it just because someone else buys it.

No. If it's not the music that I particularly like, I won't pay the corresponding fees casually and I can borrow their corresponding services.

No, unless I have a need.

No. Because I think whether I subscribe to this service should be based on my own needs, rather than blindly following others' decisions.

No, because the wallet is empty.

No, because just knowing that people around me have subscribed cannot stimulate my consumer demand, and what others need services is not necessarily what I need.

\section{A Short Interview Summary for Those Supporting Paying for Music}

Yes. I would like to experience how good the service is for people who are important to me.

Yes. Because they use it, I think the subscription is worth it and a wise choice.

Yes, I can download songs, but I can't download songs without members.

Yes, first of all, I will consider the service. Paid services provide better music and discountssecondly, vanity. I will open a membership with others because of vanity. Third, in order to show off, I don't need these twenty dollars and I can just open a member to arrogantly.

Yes, I think music has certain social attributes. If a paid service allows me to understand each other's music preferences, it will prompt me to subscribe.

Yes. I think their choice will be of reference value to me, and the cost of trying is relatively low.

Yes. There will be a need.

Yes, because I think it's convenient for sharing songs with friends.

Yes, because I want to enjoy better service.

Yes, because a friend's use will make me think that this service might be worth my money. 
Figure 4. Survey on music streaming

Survey on the premium service subscription of music streaming platforms in China

关于中国流媒体音乐服务中会员㹝阅项目的相关调查

Introduction of the project: We are conducting this research project in order to get a better understanding of Chinese music consumers' attitude and buying intentions toward paid streaming music services (i.e. Netease, $\mathrm{QQ}$, Xiami, Apple Music). Your participation is of great importance to us, as your responses would be transformed into qualitative data for further analysis and insights.

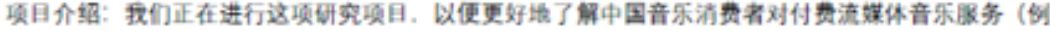

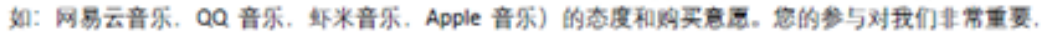

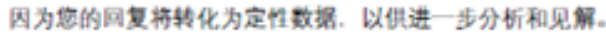

Introduction of the investigators: This research project is conducted as one part of an FYP project, the primary investigator of this project is Mr Yifan Yane, who can be contacted at Yifan.Yane15 estudent xjtlu.edu.cn. This research project is supervised by Prot. Victor Chang and Dr. Chang Xiong from International Business School Suzhou at XITLU.

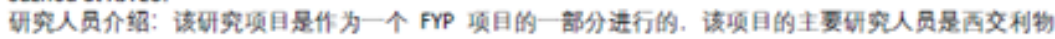

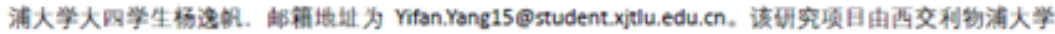

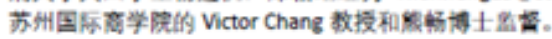

Explanation on Privacy Protection: The research data collected (i.e. your responses) would only be used for research purposes. Your name and any sensitive personal information would not be made public in any forms of publications, presentations, or posters. The participation into thk project is fully voluntary, and you have the right to opt out at any point of time.

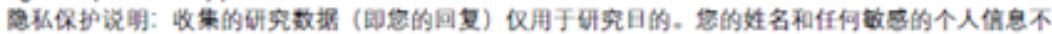

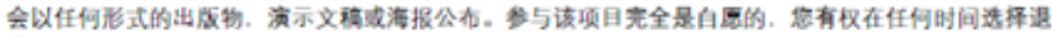
its.

Gender $/$ it 9 is

OMale / 男

OFemale / 女

Age/年数

O $10-15$ years old

O $16-20$ years old

$021-25$ years old

026 - 30 years old

O 31 - 35 years old

O 36 - 40 years old

Education level / 数有水平

OHigh school and below / 高中及以下

OCollege degree / 专科

OBachelor's degree / 채겨

OMaster's degree and above / 俓士及以上

Have vou ever subscribed to a premium service on streaming music platforms? 
Victor Chang (Prof) is a Professor of Data Science and IS at Teesside University, UK. He was a Senior Associate Professor, Xi'an Jiaotong-Liverpool University between June 2016 and Aug 2019. He was a Senior Lecturer at Leeds Beckett University, UK between Sep 2012 and May 2016. Within 4 years, he completed Ph.D. (CS, Southampton) and PGCert (HE, Fellow, Greenwich) while working for several projects. Before becoming an academic, he achieved $97 \%$ on average in 27 IT certifications. He won an IEEE Outstanding Service Award in 2015, best papers in 2012, 2015 \& 2018, 2016 European award: Best Project in Research, 2017 Outstanding Young Scientist and numerous awards since 2012. He is widely regarded as a leading expert on Big Data/Cloud/loT/security. He is a visiting scholar/PhD examiner at several universities, an Editor-in-Chief of IJOCI \& OJBD, former Editor of FGCS, Associate Editor of TII \& Info Fusion, founding chair of international workshops and founding Conference Chair of IOTBDS, COMPLEXIS, FEMIB \& IIOTBDSC. He was involved in projects worth more than £13 million in Europe and Asia. He published 3 books and edited 2 books. He gave 18 keynotes internationally as a top researcher.

Yifan Yang graduated with BSc IMIS from Xi'an Jiaotong-Liverpool University, China. He was under Prof Chang's supervision. He's currently pursuing MSc in Business Analytics at Xi'an Jiaotong-Liverpool Universitunder Dr. Xiong's supervision.

Qianwen Ariel Xu completed MSc Business Analytics with Distinction from the University of Liverpool and Xi'an Jiaotong-Liverpool University in 2020. She has worked with Prof. Victor Chang in the last 2 year part-time. She is a capable, efficient and hardworking researcher under Prof Chang's guidance. She will work towards her PhD under Prof Chang's supervision.

Chang Xiong $(P h D)$ is a Lecturer at HeXie Management Research Centre, Xi'an Jiaotong-Liverpool University, China. He has a PhD degree in Management from The University of Liverpool. Prior to his PhD study, he has completed a Master's degree in Economics from the University of Manchester in 2015. He is trained to conduct both qualitative and quantitative research within a range of management/marketing topics. Previously he has also worked as a Research Assistant at SKEMA Business School Suzhou campus, where he was involved in a variety of collaborative research projects with Tongji University and Shanghai University of Finance and Economics. 